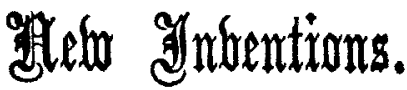

\section{IMPROVED MOUTH GAG.}

Mr. W. R. Ackland, dental surgeon to the Royal Infirmary, Bristol, has suggested to Messrs. Arnold and Sons, West Smithfield, a modification of the jaws of Mason's and like mouth-gags. The innovation consists in making the

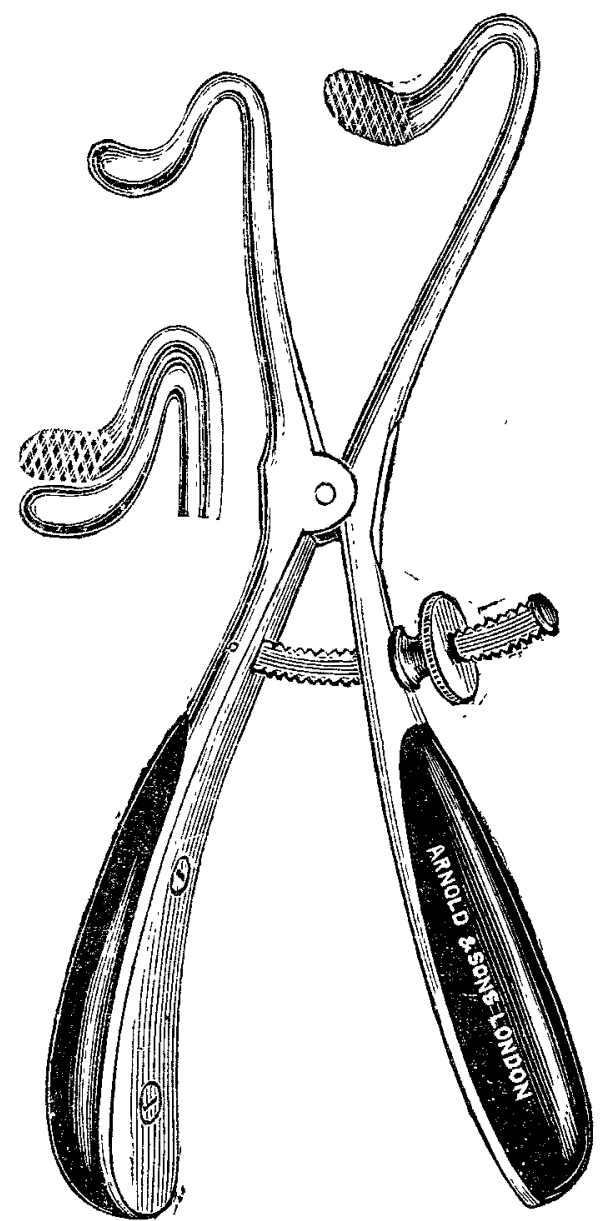

Figure showing appearance of blades both when open and shut.

rubber-covered noses to close edge to edge instead of exactly over one another. By this modification a thinner wedge is presented for insertion between the clenched teeth, which will be found advantageous in use.

\section{THE ORIOLE PILLOW SLING.}

I HAVE found the Oriole Pillow sling to be of so much assistance in the treatment of spasmodic asthma or cardiac and renal asthma that $I$ am willing to assist in bringing it under the notice of the medical profession. It is far superior to the ordinary bed rest. The pillow does not lie on the bed, but on a piece of strong canvas supported by straps fastened to the top and bottom rails of the bedstead. The makers are Messrs. Lipsett and Co., 21, Leece-street, Liverpool. I have only a slight acquaintance with the inventor.

Gambier-terrace, Liverpool. Alexander Davidson, M.D. Edin., \&c.

\section{THE TRIPLE SPRING TRUSS.}

Mr. K. R. SснRамm, of 24, Great Castle-street, Carendishsquare, has sent us a truss of a new design, in which the pad is not immorably attached to the spring, but is capable of a considerable range of adjustment at the discretion of the wearer. This unquestionable advantage is not obtained by any complex arrangement, nor is it attended by any sacrifice of efficiency in other respects. The end of the spring has a longitudinal row of perforations and the pad is provided with a socket in which this part of the spring slides easily and with very little shaking. On the front of the pad there is a small spring catch, the point of which can be passed through a hole in the side of the socket into any one of the holes in

the spring, and the pad is thereby securely fixed in the position which the wearer finds most useful. The springs are easily detached, as there are no screws, neither are there any loose parts which might fall off or be mislaid. The springs

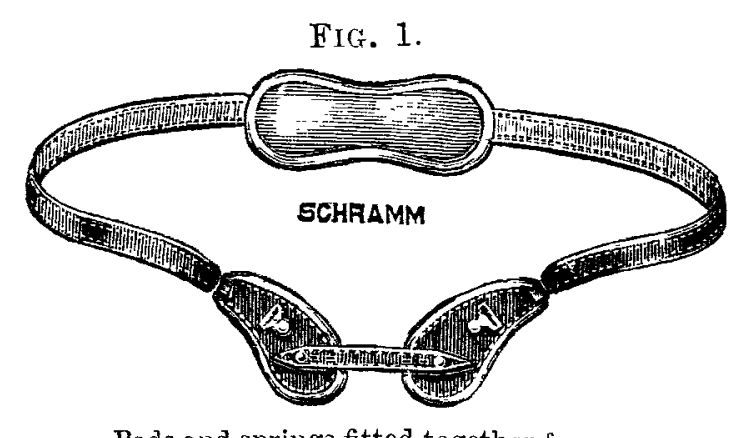

Pads and springs fitted together for use.

can also be detached from the back pad and replaced by weaker or stronger ones as required. The name "Triple Truss" refers to the three strengths of springs that may be

FIG. 2.

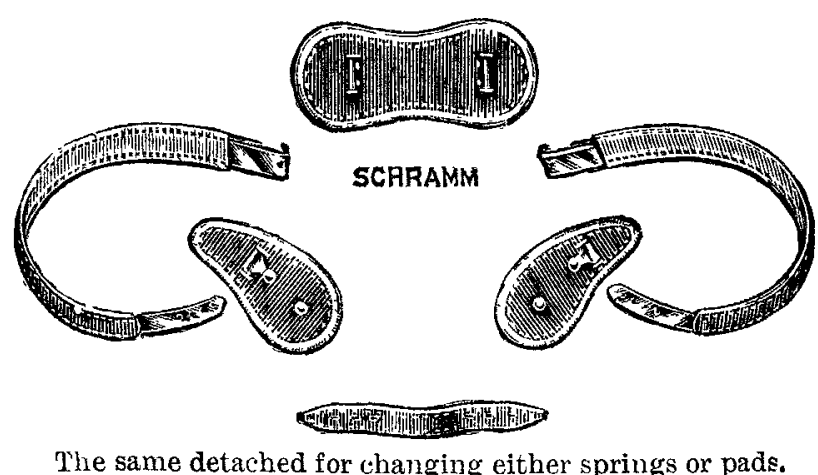

used. The pads are stuffed with horsehair, and the metal parts are nickel-plated. Both the design and the workmanship are good.

\section{A SANITARY FLOUR-BIN.}

THE accompanying illustration will explain the simple but important modification in the construction of this useful receptacle. It is made of galvanised steel beaten into slightly concave shape, so that no lodgment is offered for the contents or crevices presented to catch and retain the fine particles of an article like flour. Thus if the bin be filled with flour and turned upside down the whole of the contents will be discharged. This is an important provision, especially in the case of flour, some of which, being left in a crevice, would be prone to deteriorate and communicate its objection-

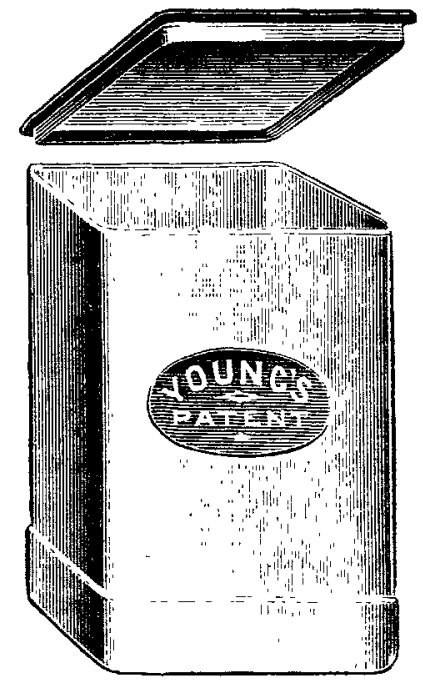

able qualities to the fresh stores of flour that may be added from time to time. The invention is an exceedingly simple one, but it is effective and is an important step towards keeping wholesome one of the most common and useful foods entering into our daily diet. The Hygienic Flour-bin, as it is called, is the invention of Mr. Percy Young of 72, Marklane, E.C. 